\title{
Perilaku Komunikasi Pengguna Aktif Instagram
}

\author{
Bayu Nugraha, M. Fakhrudi Akbar \\ Program Studi Manajemen Komunikasi Fakultas Ilmu Komunikasi Universitas Padjadjaran
}

\begin{abstract}
ABSTRAK
Tujuan penelitian ini adalah untuk mengetahui faktor-faktor yang melatarbelakangi terjadinya perilaku komunikasi pengguna aktif Instagram dan mengetahui perilaku komunikasi antar sesama pengguna aktif Instagram. Penelitian ini menggunakan metode kualitatif studi kasus. Teknik pengumpulan data menggunakan wawancara berulang kepada delapan orang informan, observasi, studi pustaka serta analisis dokumen yang berkaitan dengan penelitian ini. Hasil dari penelitian ini mengungkapkan bawah faktor-faktor yang melatarbelakangi terjadinya perilaku komunikasi pengguna aktif instagram adalah fasilitas pendukung, keinginan untuk menghasilkan karya yang lebih baik, frekuensi mengakses yang tinggi serta dorongan kerabat. Perilaku komunikasi antar sesama pengguna aktif instagram yaitu mengunggah foto, melakukan following dan unfollow, memberikan like dan komentar, membubuhi informasi pada foto yang diunggah serta menghadiri kegiatan gathering dan photowalk.

Kata kunci: Pengguna aktif Instagram, photowalk, follow unfollow
\end{abstract}

\section{Instagram Active User Communication Behaviour}

\begin{abstract}
The purpose of this study was to determine the factors behind the occurrence of communication behavior of active Instagram users and to know the communication behavior among fellow active Instagram users. This study uses a case study qualitative method. Data collection techniques using repeated interviews to eight informants, observation, literature studies and analysis of documents related to this study. The results of this study reveal that the underlying factors in the communication behavior of active users of Instagram are supporting facilities, the desire to produce better works, high frequency of access and encouragement from relatives. Communication behavior among instagram active users is uploading photos, following and unfollowing, giving likes and comments, embedding information on uploaded photos and attending gathering and photowalk activities.
\end{abstract}

Keywords: Instagram active users, photowalk, follow unfollow

Korespondensi: Bayu Nugraha. Universitas Padjadjaran. Jln. Raya Bandung-Sumedang Km 21 Jatinangor.Email: bayunugraha@gmail.com

\section{PENDAHULUAN}

Media sosial sekarang ini adalah sesuatu yang populer dan revolusioner. Hal ini ditandai dengan banyaknya pengakses media sosial, jenis media sosial yang bermunculan serta makin berkembangnya teknologi pengakses media sosial tersebut.

"Menurut Forrester Research, 75\% peselancar internet menggunakan media sosial pada kuartal kedua tahun 2008 untuk bergabung 
dengan jejaring sosial, membaca blog, atau

(Community), dan Keterhubungan memberikan ulasan kepada situs (Connectedness)."

perbelanjaan. Oleh karena itu wajar untuk mengatakan bahwa Media Sosial merupakan sebuah tren baru yang revolusioner yang harus menarik bagi perusahaan yang beroperasi di online space - atau ruang apapun, dalam hal ini." (Kaplan \& Haenlein, 2010). Media sosial juga penting karena penelitian yang dilakukan oleh Wahyudin, Ronauli, Elita, Mirawati (2016:125) menunjukkan bahwa pesan melalui media sosial berpengaruh terhadap sikap dan gaya hidup masyarakat. Media juga saat ini bukan hanya penyampai pesan namun menjadi pesan atau bahkan subjek yang mempengaruhi masyarakat (Gemiharto, Abdullah, Puspitasari, 2017:13)

Apa itu media sosial? Menurut Kaplan dan Haenlein (2010), Media sosial adalah sebuah kelompok aplikasi berbasis internet yang membangun di atas dasar ideologi dan teknologi Web 2.0, dan yang memungkinkan penciptaan dan pertukaran user-generated content.

Lain hal dengan Mayfield (2008), beliau punya cara tersendiri untuk mendefinisikan media sosial. "Media Sosial adalah dipahami sebagai sebuah grup dari jenis-jenis baru media online, yang membagikan sebagian besar atau semua dari beberapa karakteristik yaitu : Partisipasi (Participation), Keterbukaan (Openned), Percakapan (Conversation), Komunitas

Media sosial menyebabkan kontribusi dan umpan balik dari semua orang yang tertarik. Garis batas antara media dan audiens tidak jelas. Sebagian besar layanan media sosial terbuka kepada umpan balik dan partisipasi. Mereka mendorong pemungutan suara, komentar-komentar dan saling berbagi informasi. Tidak Seperti media tradisional yang hanya tentang "penyiaran" (konten ditransmisikan atau didistribusikan kepada pemirsa), media sosial lebih dilihat sebagai percakapan dua arah. Media sosial memungkinkan komunitas-komunitas untuk terbentuk dengan cepat dan berkomunikasi secara efektif. Komunitas komunitas membagikan ketertarikan umum, seperti komunitas pecinta fotografi, isu-isu politik atau sebuah acara tv favorit. Kemudian sebagian besar jenis media sosial mengembangkan keterhubungan mereka dengan emanfaatkan link ke situs, sumber dan orang orang. Misalnya, seorang pengguna Twitter dapat meng-link tulisan-tulisannya menjadi sebuah status di media sosial lain seperti facebook.

Beberapa media sosial yang berhasil populer belakangan ini adalah facebook pada posisi pertama dengan perkiraan 750.000.000 pengunjung perbulannya dan twitter pada posisi kedua dengan 250.000.000 pengunjung setiap bulannya. Masih ada linkedin, myspace 
dan ning di posisi berikutnya (www.ebizmba.com. diakses July 2012).

Facebook dan twitter merupkan dua jenis media sosial yang berbeda. Facebook adalah Situs jejaring sosial sedangkan twitter adalah Micro-Blog. Untuk lebih lengkapnya mengenai pengelompokan bentuk dasar dari

Media Sosial, penulis mengutip Mayfield (2008), menurut beliau ada enam jenis bentuk dasar dari media sosial, yaitu Blogs, Wikis, Podcasts, Forums, Content Communities, dan Microblogging.

Blogs mungkin adalah bentuk media sosiak yang paling dikenal, blogs adalah jurnal online. Blogs yang populer saat ini ada blogspot.com, wordpress.com, dan tumblr.com. Wikis adalah website yang memungkinkan orang-orang untuk menambahkan koneten atau mengubah informasi, berperan sebagai dokumen atau database umum. Wikis ini adalah wikipedia.

Podcasts adalah file-file audio dan video ang tersedia untuk langganan, melalui layanan seperti apple itunes. Forums adalah area untuk berdiskusi secara online, sering mengenai topik dan ketertarikan spesifik. Forum hadir sebelum kata "sosial media" dan merupakan sebuah element yang kuat dan populer dari komunitas online. Kita lihat saja kaskus.us forum dengan user terbanyak di Indonesia. Tidak jarang sebuah isu bisa menjadi besar bila isu tersebut menjadi topik yang populer di kaskus.us. Micro-blogging adalah penggabungan jejaring sosial dengan bite-sized blogging, dimana sejumlah kecil konten didistribusikan secara online. Inilah yang biasa kita sebut dengan twitter. Content Communities adalah komunitas yang mengorganisir dan membagikan kontenkonten tertentu. Content Communities yang paling populer saat ini adalah flickr.com dan youtube.com.

Untuk mengakses media sosial seorang peselancar membutuhkan sebuah perkembangan teknologi komunikasi yang dinamai internet. Internet (kependekan dari interconnection-networking) ialah sistem global dari seluruh jaringan komputer yang saling terhubung menggunakan standar Internet Protocol Suite (TCP/IP) untuk melayani miliaran pengguna di seluruh dunia (wikipedia). Diawali dari sebuah penelitian pertahanan Amerika Serikat berkembang menjadi sebuah sebuah mesin ekonomi global.

Berbagai macam kemampuan dan potensi internet sehingga memungkinkan manusia untuk saling berhubungan dan memenuhi kebutuhan komunikasi mereka secara hampir tanpa batas. Berbagai keterbatasan yang dulu dialami manusia dalam berhubungan satu sama lainnya seperti faktor jarak, waktu, jumlah, kapasitas serta kecepatan dan lain sebagainya, sekarang dapat diatasi.

Selain itu, dengan kemunculan teknologi digital dan internet ini, setiap orang dapat dengan mudah membuat konten media 
sosial mereka sendiri, baik itu gambar, katakata, video atau audio yang biasanya dibagikan melalui media sosial yang mereka gunakan. Sekarang ini saja, untuk mengakses internet, seseorang tidak harus melalui komputer ataupun laptop. Seiring perkembangan teknologi komunikasi khususnya tekonologi komunikasi nirkabel yang semakin pesat, internet dapat diakses dengan menggunakan telepon genggam, tablet pc, bahkan piranti MP4 Player seperti produksi Apple Inc. yang bernama iTouch atau iPod Touch juga dilengkapi dengan fasilitas untuk mengakses internet.

Akses tersebut dikombinasikan dengan biaya murah yang ditawarkan provider penyedia layanan internet untuk dapat mengakses internet melalui handset secara mudah. Dengan begitu setiap orang bisa mengakses media sosial saat berjalan kaki, sambil menyantap makanan, bahkan saat kuliah berlangsung.Dengan sedikit sentuhan mereka bisa menggunggah kontenkonten tersebut melalui aplikasi -aplikasi yang disediakan produsen hand-set tersebut.

Salah satu aplikasi itu adalah instagram. Instagram merupkan salah satu jenis media sosial yang kehadirannya cukup fenomenal. Dalam waktu sembilan bulan saja, unggah foto dalam Instagram mencapai angka 150 juta foto di San Francisco. Mengalahkan situs media-sharing sejenis flickr dan situs jejaring Facebook yang fenomenal. Menurut pengelompokan media sosial berdasarkan
Mayfield, Instagram ini masuk ke dalam kelompok media sosial Content Communities.

Aplikasi buatan Kevin Systrom dan Mike Krieger adalah sebuah aplikasi yang memiliki fitur efek foto. Para penggunanya dapat menikmati fitur ini untuk menyunting foto dan membuat tampilan fotonya lebih menarik. Instagram memiliki 16 efek yang dapat digunakan oleh para pengguna pada saat menyunting sebuah foto. Efek tersebut terdiri dari: X-Pro II, Lomo-fi, Earlybird, Sutro, Toaster, Brannan, Inkwell, Walden, Hefe, Nashville, 1977, Valencia, Amaro, Rise, Hudson dan Lord Kelvin.

Setelah membuat tampilan foto menjadi lebih menarik, instagram memiliki fitur lain untuk menonjolkan sisi karakteristik media sosialnya, yaitu fitur berbagi foto. Foto tersebut dapat diunggah dan dibagi dengan sesama pengguna instagram. Dari sinilah Partisipasi (Participation), Keterbukaan (Openned), Percakapan (Conversation), Komunitas (Community), dan Keterhubungan (Connectedness) yang Mayfield (2008) maksud sebagai karakteristik media sosial dimulai. Dalam Instagram, individu berinteraksi dengan individu lainnya adalah dengan menjadi pengikut akun pengguna lainnya, atau memiliki pengikut Instagram. Dengan demikian komunikasi antara sesama pengguna Instagram sendiri dapat terjalin dengan memberikan tanda suka dan juga mengomentari foto foto yang telah 
diunggah oleh pengguna lainnya. Pengikut juga menjadi salah satu unsur yang penting, dimana jumlah tanda suka dari para pengikut sangat

mempengaruhi apakah foto tersebut dapat menjadi sebuah foto yang popular atau tidak.

Berdasarkan latar belakang di atas, maka perumusan masalah dalam penelitian ini adalah: "Bagaimanakah perilaku komunikasi pengguna aktif Instagram?"

Dari segi biologis, perilaku adalah suatu kegiatan atau aktivitas organisme (makhluk hidup) yang bersangkutan. Skiner dalam Notoadmodjo (2007), merumuskan bahwa perilaku merupakan respons atau reaksi seseorang terhadap stimulus (rangsangan dari luar). Definisi perilaku yang cukup tua dikemukakan pleh Mc Donald (1960:167) yakni sebagai respon atau aksi yang dilakukan oleh seseorang atau segala sesuatu yang dilakukannya. Menurut Carey (1989), dalam sudut pandang ritual, komunikasi ditandai oleh konsep-konsep seperti berbagi, partisipasi dan pertemanan. Sudut pandang ritual memanfaatkan akar timbal balik dari istilah keawaman, persekutuan, komunitas, dan komunikasi. Hal ini dekat dengan komunikasi phatic.

\section{METODE PENELITIAN}

Penelitian ini dirancang sebagai sebuah Studi Kasus, dimana secara umum, studi kasus merupakan strategi yang lebih cocok bila pokok pertanyaan suatu penelitian berkenaan dengan how atau why, bila peneliti hanya memiliki sedikit peluang untuk mengontrol peristiwa-peristiwa yang akan diselidiki, dan bilamana fokus penelitiannya terletak pada fenomeda kontemporer (masa kini) di dalam konteks kehidupan nyata (Yin, 1996) .

Secara lebih rinci, studi kasus memiliki kunggulan-keunggulan sebagai berikut (Bungin, 2003); 1. Studi kasus dapat memberikan informasi penting mengenai hubungan antar variabel serta peroses-proses yang memerlukan penjelasan dan pemahaman yang lebih luas; 2. Studi kasus memberikan kesempatan untuk memperoleh wawasan mengenai konsep-konsep dasar perilaku manusia. Melalui penyelidikan intensif, peneliti dapat menemukan karakteristik dan hubungan-hubungan yang (mungkin) tidak diharapkan atau tidak diduga sebelumnya; 3 . Studi kasus dapat menyajikan data-data dan temuan-temuan yang sangat berguna sebagai dasar untuk membangun latar permasalahan bagi perencanaan penelitian yang lebih besar dan mendalam dalam rangka pengembangan ilmu-ilmu sosial.

Adapun metode pengumpulan data dalam penelitian ini sebagai berikut: 1 . wawancara 2. observasi 3. studi pustaka 4. analisis dokumen. Subjek penelitian terdiri dari delapan orang pengguna aktif yang 
berasal dari sebuah komunitas Kaskus Instagram Photography yang menghabiskan sebagian besar waktu luangnya untuk mengakses aplikasi instagram.

\section{HASIL DAN PEMBAHASAN}

Hasil yang diperoleh pada penelitian ini yaitu Para informan mengakui menjadi pengguna aktif aplikasi instagram ini karena beragam faktor yang melatarbelakangi, antara lain yaitu adanya fasilitas pendukung yang memungkinkan mereka mengakses dan melakukan interaksi di dalam media sosial instagram, Keinginan untuk menghasilkan karya yang lebih baik yaitu karya dalam hal foto. Karya yang dimaksud disini sudah jelas adalah karya fotografi, baik tanpa menggunakan efek ataupun menggunakan berbagai macam jenis efek. Frekuensi mengakses yang tinggi, para informan menghabiskan waktu sebanyak 6 jam sehari untuk hanya untuk mengakses instagram. Mereka mengaku selalu memegang iDevice jenis iPhone 4S miliknya, di kantor sekalipun agar dapat dengan leluasa untuk mengakses. Masing-masing pengguna aktif instagram yang menjadi informan dalam penelitian ini aktif dalam berbagai macam komunitas yang ada di instagram, minimal seorang pengguna aktif di salah satu komunitas. Salah satu komunitas tersebut adalah Kaskus Instagram Photography yang dikenal dengan ID instagram @gang_kaskus.
Setiap komunitas pasti mempunyai aturanaturan untuk anggotanya. Seperti komunitas @gang_kaskus yang mewajibkan anggotaanggotanya untuk saling memberikan tanda like kepada semua foto anggota komunitas tersebut. Selain itu, @gang_kaskus juga memiliki beberapa kegiatan rutin, diantaranya adalah \#gk_sundulmalem dan \#gk_weeklychallenge, dimana dua kegiatan rutin berhadiah cendol tersebut wajib diikuti setiap member. Perilaku komunikasi yang mereka tunjukkan adalah mengunggah foto dengan sentuhan ciri khas masing-masing, melakukan following terhadap akun pengguna lain yang disukai, melakukan unfollow dengan akun-akun yang tidak pernah atau jarang berinteraksi dengan akun mereka, memberikan tanda like terhadap semua foto milik akun yang merupakan teman mereka, memberikan komentar terhadap foto yang mereka sukai, membubuhi informasi pada foto yang diunggah berupa hashtag untuk memperbanyak viewer serta menghadiri kegiatankegiatan kopi darat seperti gathering dan photowalk untuk bertemu langsung secara tatap muka untuk mengakrabkan hubungan diantara mereka dan untuk saling bertukar pikiran mengenai teknik fotografi dan editing foto sehingga mereka dapat menyempurnakan karyanya.

\section{SIMPULAN}

Berdasarkan atas penelitian mengenai perilaku komunikasi pengguna aplikasi media 
sosial instagram, maka peneliti mengambil kesimpulan sebagai berikut: 1) Perilaku komunikasi yang mereka tunjukkan adalah mengunggah foto, melakukan following, melakukan unfollow, memberikan tanda like terhadap semua foto milik akun yang merupakan teman mereka, memberikan komentar terhadap foto yang mereka sukai, membubuhi informasi pada foto yang diunggah berupa hashtag serta menghadiri kegiatan-kegiatan kopi darat seperti gathering dan photowalk untuk bertemu langsung secara tatap muka.

\section{DAFTAR PUSTAKA}

Bungin, Burhan. 2007. Penelitian kualitatif. Pranada Media Group : Jakarta.

Gemiharto, I., Abdullah A., Puspitasari, L., 2017, Kajian Kritis Tayangan

Televisi Favorit Kelas Menengah Perkotaan, Jurnal ProTVF Volume 1 Nomor 1 diakses melalui http://jurnal.unpad.ac.id/protvf/article /view/13329

Creswell, J.W. (1998). Qualitative inquiry and research design: Choosing among five traditions. Thousand Oaks, CA: Sage Publications

Kaplan, M. Andreas \& Michael Haenlein. (2010). "Users of the World, Unite! The Challenges and Opportunities of Social Media". Kelley School Of Business : Indiana University.

LittleJohn, Stephen W. 2005 Theories of Human Communication - Fifth Edition. Terjemahan edisi Indonesia Mayfield, Antony. (2008). "What is Social Media?". iCrossing

Maslow, Abraham H. 1970. Motivation And Personality. Harper \& Row, Publishers, Inc.
Mulyana, Deddy. 2002. Metodologi Penelitian Kualitatif. Bandung. PT Remaja Rosdakarya.

Poston, Bob. 2009. Maslow's Hierarchy of Needs. Association of Surgical Technologists

Rakhmat, Jalaluddin. 2007. Psikologi Komunikasi (Edisi Revisi). Bandung. PT. Remaja Rosdakarya.

Ronauli, M., Wahyudin, U., Elita, F.U., Mirawati, I., 2016, HUBUNGAN ANTARA PESAN KAMPANYE 9 AKSI RAMAH LINGKUNGAN DI AKUN TWITTER EARTH HOUR BANDUNG DENGAN SIKAP FOLLOWERS AKTIF TERHADAP GAYA HIDUP RAMAH LINGKUNGAN, diakses dari http://jurnal.unpad.ac.id/manajemenkomunikasi/article/view/11017/4924

Sugiyono. (2008). Memahami Penelitian Kualitatif. Bandung. Alfabeta.

Villi, Mikko. 2010. Visual Mobile Communication : Camera Phone Photo Messages as Ritual Communication and Mediated Presence. Finland. ws Bookwell Ltd.

Villi, Mikko. 2011. Messaging and Publishing Photographs : Sharing Camera Phone Photographs Via The Internet. Finland. Allto University School Of Economics.

West, Richard dan Lynn H. Turner. 2008. Pengantar teori Komunikasi: Analisis dan Aplikasi.

Yin, Robert K. 1996. Studi Kasus : Desain \& Metode. Jakarta : Rajawali Pers. 